\title{
Polyamidoamine dendrimer-based binders for high-loading lithium-sulfur battery cathodes
}

Priyanka Bhattacharya*a, Manjula I. Nandasiri ${ }^{\mathrm{b}}$, Dongping Lv ${ }^{\mathrm{a}}$, Ashleigh M. Schwarz ${ }^{\mathrm{b}}$, Jens T. Darsell $^{\mathrm{a}}$, Wesley A. Henderson ${ }^{\mathrm{a}}$, Donald A. Tomalia ${ }^{\mathrm{c}}$, Jun Liu ${ }^{\mathrm{a}}$, Ji-Guang Zhang ${ }^{\mathrm{a}}$, Jie Xiao ${ }^{\mathrm{a}}$ *

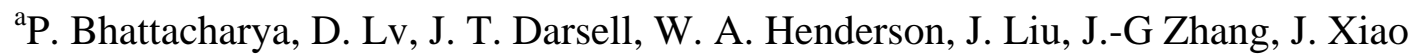
Energy and Environment Directorate, Pacific Northwest National Laboratory, Richland, WA 99352, United States

${ }^{\mathrm{b}}$ M. I. Nandasiri, A. M. Schwarz

Environmental and Molecular Sciences Laboratory, Pacific Northwest National Laboratory, Richland, WA 99352, United States

${ }^{\mathrm{c}} \mathrm{D}$. A. Tomalia

Nanosynthons LLC, 1200 N. Fancher Avenue, Mt. Pleasant, MI 48858, United States

*Corresponding author e-mail: priyanka.bhattacharya@pnnl.gov, jie.xiao@pnnl.gov

Abstract: Lithium-sulfur (Li-S) batteries are regarded as one of the most promising candidates for next generation energy storage. To realize their practical application, however, a high $\mathrm{S}$ active material loading is essential. The binder material used for the cathode is therefore crucial as this is a key determinant of the bonding interactions between the active material (S) and electronic conducting support $(\mathrm{C})$, as well as the maintenance of intimate contact between the electrode materials and current collector.

Here, we investigated the application of polyamidoamine (PAMAM) dendrimers as functional binders in Li-S batteries. Utilizing the high degree of surface functionalities, interior porosities, and polarity of the PAMAM dendrimers, it is demonstrated that high $\mathrm{S}$ loadings (>4 $\mathrm{mg} \mathrm{cm}^{-2}$ ) can be easily achieved using simple processing methods. An exceptional electrochemical cycling performance was obtained as compared to cathodes with conventional linear polymeric binders such as carboxymethyl cellulose (CMC) and styrenebutadiene rubber (SBR), which was attributed to better interfacial interactions between the dendrimers and the C/S composite materials, as well as better electrolyte wetting due to the dendrimer spherical molecular, porous architectures. Furthermore, the dendrimer-based 
binders also physically and chemically trapped the polar polysulfides, thus demonstrating the significant utility of this new nanosized binder architecture.

Keywords: PAMAM dendrimers, lithium-sulfur batteries, binder, energy storage, high sulfur loading

\section{Introduction}

An exponential rise has occurred in the research of lithium-sulfur (Li-S) batteries, resulting in significant new insights into their characteristics/challenges aiding to propel this technology towards commercialization [1]. Li-S batteries have the potential to deliver twice the gravimetric energy density of lithium-ion batteries (LIBs) [2]. To realize the practical application of Li-S batteries, a high $\mathrm{S}$ active material loading is necessary ( $>70 \mathrm{wt} \%$ in the CS composite and $>2 \mathrm{mg} \mathrm{cm}^{-2}$ in the electrode). Two particularly critical challenges to achieving this high loading are the dissolution of the longer lithium polysulfide (LiPS) intermediates in the electrolyte [3] and increasing the electronic conductivity within the cathode. However, nearly all of the published reports addressing these issues have used very low S loadings, as well as thin electrodes, and the favorable results may well be very different for high S loadings.

The effect of the binder chosen on the ability to fabricate thick electrodes and the electrochemical performance of such electrodes has been rarely investigated. For example, Sun et al. applied gelatin as a cathode binder at a modest $\mathrm{S}$ loading of $\sim 2 \mathrm{mg} \mathrm{cm}^{-2}$ [4]. A high initial capacity of $1132 \mathrm{mAh} \mathrm{g}^{-1}$ at $0.4 \mathrm{~mA} \mathrm{~cm}^{-2}$ was obtained, but the capacity retained after 50 cycles was only $408 \mathrm{mAh} \mathrm{g}^{-1}$. Zhang employed poly(acrylamide-codiallyldimethylammonium chloride) (AMAC) as an aqueous binder for a high loading $\mathrm{S}$ cathode $\left(3 \mathrm{mg} \mathrm{cm}^{-2}\right)$ delivering a high initial capacity $\left(1049 \mathrm{mAh} \mathrm{g}^{-1}\right)$ at $0.2 \mathrm{~mA} \mathrm{~cm}^{-2}$ and a capacity retention of $652 \mathrm{mAh} \mathrm{g}^{-1}$ at the end of 100 cycles at $0.5 \mathrm{~mA} \mathrm{~cm}^{-2}$ [5]. Huang et al. 
compared the performance of $\mathrm{S}$ cathodes with $2 \mathrm{mg} \mathrm{cm}^{-2}$ of $\mathrm{S}$ with aqueous gelatin and poly(ethylene oxide) (PEO) as binders [6]. The gelatin-based cathodes had a higher initial discharge capacity $\left(1132 \mathrm{mAh} \mathrm{g}^{-1}\right)$ than the PEO-based cathodes $\left(996 \mathrm{mAh} \mathrm{g}^{-1}\right)$ at $0.4 \mathrm{~mA} \mathrm{~cm}^{-}$ ${ }^{2}$. The better performance using the gelatin binder was attributed to an enhanced redox reversibility of the S. Another water-soluble binder recently explored for S cathodes is LA132 $\left(-\left[-\mathrm{R} 1-\mathrm{R} 2-\mathrm{CH}_{2}-\mathrm{CH}(\mathrm{CN})\right]_{\mathrm{n}}{ }^{-}\right)[7]$. At $5 \mathrm{wt} \%$, cathodes with the LA132 binder exhibited a reversible discharge capacity of $470 \mathrm{mAh} \mathrm{g}^{-1}$ at a $\mathrm{C} / 2$ rate over 100 cycles, thus having a remarkably improved cyclability as compared with the traditional poly(vinylidene fluoride) (PVDF)-based cathodes. This improvement was credited to a smaller internal resistance and better kinetic characteristics in the LA132-based cathodes. The LA132 cathodes also suppressed the agglomeration of $\mathrm{Li}_{2} \mathrm{~S}_{2} / \mathrm{Li}_{2} \mathrm{~S}$ and maintained the porous structure of the $\mathrm{S}$ cathode. In another study, Jung and Kim investigated a mixed polymer binder system comprised of polyvinylpyrrolidone (PVP) and polyethyleneimine (PEI) resulting in a S loading of $2.4 \mathrm{mg} \mathrm{cm}^{-2}$ [8]. The discharge capacity at the 50th cycle was found to be $580 \mathrm{mAh}$ $\mathrm{g}^{-1}$ with an $83 \%$ capacity retention from the initial capacity $\left(\sim 720 \mathrm{mAh} \mathrm{g}^{-1}\right)$ at a high current density of $2.0 \mathrm{~mA} \mathrm{~cm}^{-2}$. The polymer blend provided an optimal viscosity for slurry coating. Seh et al. also investigated PVP as a bifunctional binder for $\mathrm{Li}_{2} \mathrm{~S}$ cathode with $2 \mathrm{mg} \mathrm{Li}_{2} \mathrm{~S} \mathrm{~cm}^{-2}$ loading and capacity retention of up to $760 \mathrm{mAh} \mathrm{g}^{-1}$ over 500 cycles at a rate of $\mathrm{C} / 5$ [9].

All of the above studies utilized binders with linear polymer morphology. The binder in the electrode is critical in bonding the active materials together, as well as maintaining intimate contact between the electrode and the current collector. Furthermore, additional functionality of the binders for physically and/or chemically restricting the dissolution of the LiPSs in the electrolyte and thus enhancing the cell cyclability is highly desirable. In the present work, commercial polyamidoamine (PAMAM) dendrimers-highly branched, synthetic and porous macromolecular architectures with a high degree of surface functional groups, symmetrical structure and well-defined interiors (Scheme 1) —-have been used as 
functional water-soluble binders for high S-loading Li-S battery cathodes [10]. The high surface functional group density of dendrimers is expected to afford larger number of possible binder-carbon/S interactions. Moreover, the high curvature of the dendrimers and their porosity allows $\mathrm{S}$ particles to be exposed to the electrolyte, thus enhancing wetting of the thick electrode. PAMAM dendrimers also contain a high density of nitrogen and oxygencontaining groups, which are expected to further immobilize the soluble polysulfide, thus mitigate the shuttling reactions [11], making them functional binders. The interior porosities of the dendrimers are in the range of $2 \mathrm{~nm}$ [12], thus allowing sufficient volume to physically trap polysulfides, whose chain lengths have been estimated to be on the order of 1.0-1.8 nm [13]. By using dendrimers as functional binders, it is demonstrated to be possible to achieve practically high $\mathrm{S}$ loadings $\left(>4 \mathrm{mg} \mathrm{cm}^{-2}\right.$ ) and a superior electrochemical performance (as compared to cathodes with conventional linear polymeric binders such as carboxymethyl cellulose (CMC) and styrene-butadiene rubber (SBR)) with >100 cycles and 85-98\% capacity retention, thus introducing a new binder architecture with exceptional physicochemical properties and critical nanoscale design parameters (CNDP's). It is noteworthy that the dendrimer-based binders were used with carbon cathodes, which were not engineered in any specialized manner, thus making the process commercially viable. Furthermore, the use of water as a solvent for cathodes processing reduces the cost and unfavorable toxic effects of the organic solvents (e.g., $N$-methyl-2-pyrrolidone, NMP) typically used to disperse binders such as PVDF.

\section{Experimental}

\subsection{Preparation of electrode slurry and fabrication of cathodes}

All cathode slurries were prepared in aqueous solvents. A carbon/sulfur (C/S) composite was prepared by mechanically mixing $80 \mathrm{wt} \% \mathrm{~S}$ (Sigma Aldrich) and $20 \mathrm{wt} \%$ Super-P carbon (Timcal) in a mortar-pestle and then melt-diffusing the $\mathrm{S}$ inside the pores of the Super-P in a 
Teflon-lined stainless steel autoclave at $155^{\circ} \mathrm{C}$ by ramping the temperature at a $5{ }^{\circ} \mathrm{C} \mathrm{min}^{-1}$ rate for $12 \mathrm{~h}$. PAMAM dendrimers with six different types of functional groups were investigated as binders for the Li-S battery cathodes. The G4CMP dendrimers were purchased from NanoSynthons LLC (MW = 22,313.4) as solids. The G4OH $(\mathrm{MW}=14,279), \mathrm{G}_{4} \mathrm{NH}_{2}$ $(\mathrm{MW}=14,215), \mathrm{G} 4 \mathrm{SA}(\mathrm{MW}=20,615), \mathrm{G} 4 \mathrm{OH}(75 \%)-\mathrm{NH}_{2}(25 \%)(\mathrm{MW}=14,215)$, and G4COONa (MW = 12,931) dendrimers were obtained from Dendritech Inc. in methanol and/or aqueous solutions. The methanol was removed prior to preparing the aqueous binder solutions. The dendrimers were used as-received. All dendrimers have 64 surface functional groups per dendrimer macromolecule and an average hydrodynamic diameter of $\sim 4 \mathrm{~nm}[12]$. The C/S/MWCNT/binder slurries were prepared by mixing $85 \mathrm{wt} \%$ prepared $\mathrm{C} / \mathrm{S}$ composites with $5 \mathrm{wt} \%$ MWCNT (Sigma Aldrich) and $10 \mathrm{wt} \%$ binder in distilled water on a magnetic stirrer for $72 \mathrm{~h}$ to ensure adequate interactions between the binders and the C/S/MWCNT composites. This was assessed as sufficient time for the proper mixing of the composites with the binders. A few drops of 2-propanol were added to the C/S/MWCNT composites prior to adding the aqueous binder solutions to enhance wetting of the carbon. The slurry obtained was thick and had a high resistance to flow. This slurry was then coated onto a carbon-coated aluminum foil current collector using a doctor-blade with $350 \mu \mathrm{m}$ wet-thickness. The coated slurry was allowed to air-dry for $1 \mathrm{~h}$, and then dried in a vacuum oven for $12 \mathrm{~h}$ at $50{ }^{\circ} \mathrm{C}$. Finally, $0.95 \mathrm{~cm}^{2}$ cathodes were punched out and dried in the vacuum oven at $50{ }^{\circ} \mathrm{C}$ for $12 \mathrm{~h}$ before their transfer into an argon-filled glove box for coin-cell assembly. The corresponding S loadings in the G4OH, G4CMP and G4COONa based electrodes were 3.89, 4.38 and 4.28 $\mathrm{mg} / \mathrm{cm}^{2}$, respectively. The CMC-SBR binder based cathodes were prepared similar to the ones with the dendrimers. Specifically, $10 \mathrm{wt} \% \mathrm{CMC}(4 \mathrm{wt} \%)-\mathrm{SBR}(6 \mathrm{wt} \%)$ binders were added to an aqueous dispersion of the $90 \mathrm{wt} \% \mathrm{C} / \mathrm{S} / \mathrm{MWCNT}$ composite and mixed for $72 \mathrm{~h}$ on a magnetic stirrer. The electrode coatings were done similar to the ones with the dendrimers. The loading of S in the CMC-SBR binder based electrodes was $\sim 2.34 \mathrm{mg} \mathrm{cm}^{-2}$. 
All of the dendrimer-based electrodes had an average of $67-71 \mathrm{wt} \% \mathrm{~S}$ content, except for the

CMC-SBR-based electrodes, which had a $58 \mathrm{wt} \% \mathrm{~S}$ loading (measured by TGA, Figure S1).

\subsection{Coin cell preparation and electrochemical testing}

Coin cells (CR2032, MTI Corp.) were assembled in a MBraun glove box with $\mathrm{O}_{2}$ and $\mathrm{H}_{2} \mathrm{O}$ content $<5$ ppm and $1 \mathrm{ppm}$, respectively. Lithium metal foil was used as the anode and polypropylene Celgard 2400 was used as the separator. The electrolyte was $1 \mathrm{M}$ lithium bis(trifluoromethanesulfonyl)imide (LiTFSI) dissolved in a mixture of 1,3-dioxolane and dimethoxyethane (1:1 in volume) with $0.2 \mathrm{M} \mathrm{LiNiO}_{3}$ added as an additive to help passivate the surface of the lithium anode and reduce the shuttle effect. The electrochemical performance was measured galvanostatically at various $\mathrm{C}$ rates $\left(1 \mathrm{C}=1673 \mathrm{~mA} \mathrm{~g}^{-1}\right)$ in a voltage range of 1.7-2.8 V on a Lanhe CT 2001A battery tester at room temperature. The charge/discharge specific capacities were calculated based on the mass of $S$ in the electrodes.

\subsection{Characterization techniques}

X-ray photoelectron spectroscopy (XPS) was performed using a Kratos Axis Ultra DLD spectrometer, which consists of a high performance Al Ka monochromatic X-ray source $(1486.6 \mathrm{eV})$ and a high-resolution spherical mirror analyzer. All of the cycled electrodes were washed three times with dimethoxyethane, dried in the glove box overnight, and hermeticallysealed in polymer-coated aluminum foil pouches in order to transfer the samples to a glove box attached to the XPS instrument to avoid contact with air. All of the pristine electrodes were transferred directly to the XPS instrument. The XPS spectra of the neat dendrimers were collected by drop-casting films of aqueous dendrimer solutions on silicon wafers. The X-ray source was operated at $150 \mathrm{~W}$ and the emitted photoelectrons were collected at the analyzer entrance slit normal to the sample surface. The data acquisition was carried out in hybrid mode with analysis area of $700 \times 300 \mu \mathrm{m}$. The survey spectra were recorded at a pass energy 
of $160 \mathrm{eV}$ with a $0.5 \mathrm{eV}$ step size and high resolution spectra were recorded at a pass energy of $20 \mathrm{eV}$ with a step size of $0.1 \mathrm{eV}$. The $20 \mathrm{eV}$ pass energy in the $700 \times 300 \mu \mathrm{m}$ analysis area is referred to the FWHM of $0.59 \mathrm{eV}$ for $\mathrm{Ag} 3 \mathrm{~d}_{5 / 2}$. A charge neutralizer with low energy electrons was used to exclude the surface charging effects and the binding energy of $\mathrm{C} 1 \mathrm{~s}$ at $284.8 \mathrm{eV}$ was used as the charge reference. The chamber pressure was maintained at $\sim 5 \times 10^{-9}$ torr during the measurements. XPS data were analyzed by CasaXPS software using Gaussian/Lorentzian (GL(30)) line shapes and Shirley background correction. ATR-FTIR characterization of the dendrimer solids and electrode samples was done using a Thermo Scientific Nicolet iS10 FT-IR spectrometer at ambient temperature with a $4 \mathrm{~cm}^{-1}$ resolution.

The mass of the $\mathrm{S}$ was measured by thermogravimetric analysis (TGA) using a Netzsch STA 449C Jupiter (STA, Simultaneous Thermal Analysis, both differential scanning calorimetry, DSC, and thermogravimetric analysis, TGA) equipped with a high-temperature SiC furnace and a type-S sample carrier. The temperature and DSC signal was calibrated using indium, $\mathrm{CsCl}$, silver and gold standards. The mass balance was calibrated with a calibration weight. The sample and reference crucibles used in these experiments were $99.8 \%$ alumina with less than $0.1 \% \mathrm{Na}_{2} \mathrm{O}, 0.07 \% \mathrm{SiO}_{2}, 0.05 \% \mathrm{CaO}$, and $0.04 \% \mathrm{Fe}_{2} \mathrm{O}_{3}$. All of the experiments were performed by heating the samples $(\sim 10 \mathrm{mg})$ at $10{ }^{\circ} \mathrm{C} \mathrm{min}^{-1}$ from room temperature to $520{ }^{\circ} \mathrm{C}$ in dry argon flowing at a rate of $60 \mathrm{ml} \mathrm{min}{ }^{-1}$.

The morphology of the samples was observed with a dual focused ion beam (FIB) scanning electron microscope (SEM) (Environmental, FEI Helios) at $5 \mathrm{kV}$. The samples were transferred to the SEM facility in aluminum foil pouches hermetically-sealed in an argon atmosphere, and then quickly transferred into the instrument to minimize air and moisture contamination.

\section{Results and discussion}

\subsection{Characterization of dendrimer binding with the carbon/sulfur composite}


The incorporation of the Generation-4 PAMAM dendrimers with hydroxyl (G4OH), 4carboxymethylpyrrolidone (G4CMP) or carboxylate (G4COONa) surface functional groups into the $\mathrm{S}$ cathodes was done by simply mixing aqueous solutions of the dendrimers with the Super-P carbon-sulfur (C/S) composites. Multi-walled carbon nanotubes (MWCNT) (5 wt\%) were also added to the $\mathrm{C} / \mathrm{S}$ composite as a conductive additive. The final ratio of C/S:MWCNT:dendrimers was 85:5:10. The chemical binding between the dendrimers and C/S/MWCNT composites was examined by X-ray photoelectron spectroscopy (XPS) and attenuated-total reflectance Fourier transform infrared spectroscopy (ATR-FTIR). Figure 1a shows the high-resolution S2p XPS spectra of the pristine C/S/MWCNT composite and the electrodes with the G4OH and G4CMP binders. The main S2p doublet at $164.3 / 164.5 \mathrm{eV}$ is associated with the $\mathrm{C}-\mathrm{S}$ bonds in the $\mathrm{C} / \mathrm{S} / \mathrm{MWCNT}$ composite, which do not change with the introduction of the dendrimers. However, sulfate $\left(\mathrm{SO}_{4}{ }^{2-}\right)$ and sulfite $\left(\mathrm{SO}_{3}{ }^{2-}\right)$-like species were observed in the dendrimer-based electrodes, which can be attributed to the oxidation of the S. The absence of such species in the pristine C/S/MWCNT composite suggests that interactions occurred between the $\mathrm{O}$ groups in the dendrimers and the $\mathrm{S}$ in the C/S/MWCNT composite electrode samples. Such S-O interactions have been previously observed to be enabled by nitrogen functional groups present in the carbon matrix in the vicinity of the oxygen functional groups [11], much like the close proximity of these functional groups in the dendrimers used here. There is no significant chemical shift in S2p doublets between the dendrimer-based electrodes suggesting a similar chemical environment for the $\mathrm{S}$ interactions. However, the G4CMP-based electrode showed the highest amount of sulfate and sulfite (36 at $\%$ ), relative to the $\mathrm{G} 4 \mathrm{OH}$ and $\mathrm{G} 4 \mathrm{COONa}$-based electrodes (25 at\%), indicating stronger S-O interactions.

The peak at $401.7 \mathrm{eV}$ in the N1s spectra (Figure $1 \mathrm{~b}$ ) of the neat dendrimers is attributed to the n-alkylamide nitrogen groups in the dendrimer interior $(-\mathrm{NH}-\mathrm{C}=\mathrm{O})$, whereas the peak at $399.6 \mathrm{eV}$ is attributed to the tertiary amine and pyrrolic nitrogens $(\mathrm{N}-5)$. A 
noteworthy shift of about $1 \mathrm{eV}$ was observed for both of these $\mathrm{N}$-groups in the electrode samples indicating N-S interactions. It has been reported that the binding energy of N1s can be increased by $1-2 \mathrm{eV}$ due to the adsorption of complexes such as sulfate and sulfite [14]. The C1S XPS spectra with the $\mathrm{C}-\mathrm{N}$ and $\mathrm{N}-\mathrm{C}=\mathrm{O}$ characteristic dendrimer peaks (Figure 1c), on the other hand, confirm the presence of dendrimers in the C/S/MWCNT/dendrimer-based electrodes, even though the dendrimer peak intensities in the electrodes are low due to their low concentration $(\sim 10 \mathrm{wt} \%)$. This confirms, however, that the dendrimers are stable during the slurry making process. It is difficult to draw conclusions on the interactions between the dendrimers and the C/S/MWCNT composite based upon the C1s spectra due to the overlap of the dendrimer carbon peaks with the $\mathrm{C}-\mathrm{S}$ and $\mathrm{C}=\mathrm{O}$ peaks in the functional groups of the C/S/MWCNT composite. The O1s spectra of the C/S/MWCNT composite, neat dendrimers, and electrodes are shown in Figure 1d. The C/S/MWCNT composite was found to contain a small amount of $\mathrm{O}$ (3 at\%), probably from functional groups on MWCNTs. The O1s spectra also indicate the $\mathrm{S}-\mathrm{O}$ interactions between the dendrimers and $\mathrm{C} / \mathrm{S} / \mathrm{MWCNT}$ composite, as discussed above for the S2p spectra, with the presence of sulfate/sulfite peaks around 532.5 $\mathrm{eV}$. However, it is challenging to interpret the peak shifts in the $\mathrm{C}-\mathrm{O}-\mathrm{C}, \mathrm{C}-\mathrm{O}-\mathrm{H}$, and $\mathrm{C}=\mathrm{O}$ peaks due to the large overlap between these peaks from the dendrimers and the C/S/MWCNT composites. The high-resolution XPS spectra of the binding between the G4COONa dendrimers and the C/S/MWCNT composites are shown in Figure S2. Similar observations as for the G4CMP and G4OH dendrimer-based electrodes were made for the G4COONa-based electrodes.

The interactions between the dendrimers and the C/S/MWCNT composites were also verified by ATR-FTIR (Figure S3). For example, the two C-N stretching vibration frequencies between 1150-1202 $\mathrm{cm}^{-1}$ for all the dendrimers become one broad band and shift toward lower frequency, implying possible hydrogen bonding (H-bonding) with the $\mathrm{O}$ groups on the $\mathrm{C} / \mathrm{S} / \mathrm{MWCNT}$ composites. A similar observation is made with the $\mathrm{C}-\mathrm{O}$ stretching 
frequency around $1260 \mathrm{~cm}^{-1}$. The relative decrease in the intensities of the amide groups (1540-1640 $\mathrm{cm}^{-1}$ ) also suggests H-bonding with defects on the carbon. In the G4CMP electrode, in addition to the above interactions, the $\mathrm{C}=\mathrm{O}$ of the ester group $\left(1732 \mathrm{~cm}^{-1}\right)$ was also observed further substantiating the presence of the dendrimers within the composite. For the $\mathrm{G} 4 \mathrm{OH}$ dendrimer, the $\mathrm{C}-\mathrm{O}$ stretching of alcohols at $1264 \mathrm{~cm}^{-1}$ becomes sharper when added to the electrode, implying H-bonding with the defects in the carbon matrix. The detailed peak shifts have been tabulated in Table S1.

The above data demonstrated that:

- $\quad$ simply mixing the dendrimers and non-engineered carbon-S composites in aqueous solvents is sufficient to induce strong binding;

- the high degree of surface functionalities on the dendrimers provide multiple binding sites with the C/S/MWCNT composite materials; and

- $\quad$ strong binding occurs between the C/S/MWCNT composites and the hydroxyl (G4OH), 4-carboxymethylpyrrolidone (G4CMP) and carboxylate (G4COONa) functional groups.

The poor binding of amine $\left(\mathrm{G} 4 \mathrm{NH}_{2}\right)$, mixed hydroxyl-amine $\left(\mathrm{G} 4-\mathrm{NH}_{2}-\mathrm{OH}\right)$ and succinamic acid (G4SA) terminated dendrimers with the C/S/MWCNT composites was also investigated and the results are discussed below and shown in the Supplementary Information. Poor interactions between $\mathrm{NH}_{2}$ and $\mathrm{COOH}$ functionalities and $\mathrm{S}$ have been observed before [15].

\subsection{Electrochemical performance of dendrimer-based binders in Li-S batteries}

The electrochemical performance of the dendrimer-based binders in high-loading S cathodes (all around $4 \mathrm{mg} \mathrm{cm}^{2}$ ) is presented in Figure 2 (G4CMP and G4OH) and Figure S4 (G4COONa). All of the cells were discharged at a $\mathrm{C} / 20$ rate $(1 \mathrm{C}=1673 \mathrm{~mA} / \mathrm{g})$ for the first two cycles to condition the electrodes with the electrolyte. Further cycling data were collected at $\mathrm{C} / 5$ between $1.7-2.8 \mathrm{~V}$ vs. $\mathrm{Li} / \mathrm{Li}^{+}$. High initial capacities were obtained: $1092 \mathrm{mAh} \mathrm{g}^{-1}$ for 
G4OH (Figure 2a), $1045 \mathrm{mAh} \mathrm{g}^{-1}$ for G4CMP (Figure 2b), and $971 \mathrm{mAh} \mathrm{g}^{-1}$ for G4COONa (Figure S4) for the $\mathrm{C} / 20$ rate. Excellent cycling stabilities were achieved for the cells, with $98 \%$ capacity retention after 100 cycles for the G4CMP-based electrode, relative to the first cycle at $\mathrm{C} / 5,85 \%$ for the $\mathrm{G} 4 \mathrm{OH}$-based electrode, and $73 \%$ for the G4COONa-based electrode. A capacity increase is observed during the first 20 cycles for G4OH and G4CMP possibly due to the improved wetting with cycling [16]. The G4CMP electrodes also show a high areal capacity of $4.56 \mathrm{mAh} \mathrm{cm}^{-2}$ at $\mathrm{C} / 20$ and $2.8 \mathrm{mAh} \mathrm{cm}^{-2}$ at $\mathrm{C} / 5$. Similarly high areal capacities were also obtained from the $\mathrm{G} 4 \mathrm{OH}$ and G4COONa binders, thus making this study practically applicable.

Notably, no electrolyte pre-wetting steps were taken before cycling the cells, nor were the electrodes specially engineered to enhance electrolyte wetting, demonstrating that the high curvature of the dendrimer binder and its porosity allows $\mathrm{S}$ particles to be exposed to the electrolyte thereby enhancing wetting. The porous nature of the pristine electrode (Figure 3a) is retained even after extended cycling, as can be seen in the SEM images in Figures $3 \mathrm{~b}$ and 3c. In contrast, the discharged CMC-SBR binder-based electrode has very little porosity after the deposit of the thick $\mathrm{Li}_{2} \mathrm{~S}$ discharge product (Figure S5c). The voltage profiles of the dendrimer binder-based cells are shown in Figures 2 and S4. The typical two discharge plateaus at $2.3 \mathrm{~V}$ and $2.0 \mathrm{~V}$ are observed for all the cells with minimal polarization, indicating that the dendrimer-based cathodes have the same electrochemical behavior as conventional S electrodes. On the other hand, the poor electrochemical behavior of the CMC-SBR binder under similar testing conditions is evident in Figures S5a and S5b. The highest S loading that could be achieved with the linear CMC-SBR binder was $\sim 2.34 \mathrm{mg} \mathrm{cm}^{-2}$ when the same carbon host e.g. Super $\mathrm{P}$ was used. Fast capacity fading and high polarization were observed in these cells. On disassembling the cells after several cycles, most of the cathode material was observed to be detached from the current collector. Despite the functional groups $(-\mathrm{OH})$ on the CMC-SBR molecules being similar to those on the $\mathrm{G} 4 \mathrm{OH}$ dendrimers, the increased 
polarity of the dendrimers relative to the $\mathrm{CMC}$ polymer chains and a uniform distribution of the surface groups ensures better interfacial interactions between the dendrimer functional groups and the carbon/S particles, as well as better adhesion to the substrate.

\subsection{Analysis of LiPS interactions with dendrimer binders}

The dendrimer-based electrodes show a superior rate performance with $93 \%$ capacity retention at $\mathrm{C} / 10$ after cycling at high rates (Figure S6). This exceptional rate performance is attributed to the unique structure of the cathode, as illustrated in Scheme 1, which not only guarantees good adhesion of the electrode materials to the current collector and excellent wetting, but also effectively retains the soluble LiPS within the pores and reduces the agglomeration of LiPS. To support this assumption, XPS measurements of the cycled electrodes were conducted after 50 cycles. Figure 4 shows the S2p, O1s, and Li1s high resolution XPS scans of the cycled G4CMP and G4OH dendrimer-based electrodes. These electrodes were chosen due to their better electrochemical performance, as compared with the G4COONa-based electrodes where some capacity fading was observed. The S2p spectra (Figure 4a) have a strong contribution from $\mathrm{Li}_{2} \mathrm{~S}(\mathrm{~S} 2 \mathrm{p}$ doublet at $160.4 / 161.6 \mathrm{eV})$ in both of the discharged electrodes, indicating the full reduction of S in the electrode [17]. The charged electrodes also indicate the presence of longer chain polysulfides $\left(\operatorname{Li}_{2} \mathrm{~S}_{\mathrm{x}}\right)$ with the $\mathrm{S} 2 \mathrm{p}$ doublets at 161.9/163.1 and 163.3/164.5 eV, ascribed to terminal $\left(\mathrm{S}_{T}^{-1}\right)$ and bridging $\left(\mathrm{S}_{B}{ }^{0}\right) \mathrm{S}$ atoms, respectively [17]. This indicates a strong binding of the long chain polysulfides within the electrodes. However, when compared with the G4CMP-based electrode, a higher amount of $\mathrm{Li}_{2} \mathrm{~S}$ is observed in the $\mathrm{G} 4 \mathrm{OH}$ electrodes after charging. It has been previously reported that charging of $\mathrm{Li}_{2} \mathrm{~S}$ and $\mathrm{Li}_{2} \mathrm{~S}_{2}$ is incomplete in DOL:DME based electrolytes [18]. The higher presence of these species in the charged G4OH electrode supports the explanation for its faster capacity fading upon cycling, relative to the electrode with G4CMP. The deconvoluted O1s spectra (Figure 4b) show the presence of $\mathrm{Li}-\mathrm{O}(531.3 \mathrm{eV})$ interactions 
between the LiPSs and the O-groups on the dendrimer based electrodes [19]. Such oxygencontaining functional groups have been previously reported to prevent the polysulfide shuttle mechanism [20]. The Li1s spectra (Figure 4c) of the charged and discharged electrodes with both G4CMP and G4OH show two peaks at 54.6 and $55.4 \mathrm{eV}$, associated with the Li-S interactions in the LiPSs and the Li-O interactions between the LiPSs and electrodes, respectively [21]. Thus, XPS provides conclusive evidence of the strong binding between the O groups within the dendrimer-based electrodes and the LiPSs, further supporting the conclusion that the functionality of the dendrimer-based binders arrests the dissolution of the LiPSs and, in turn, enhances the electrochemical cycling stability of Li-S batteries with electrodes having a high $\mathrm{S}$ loading.

Seh et al. have performed ab-initio simulations previously to aid in understanding $\mathrm{Li}_{2} \mathrm{~S}$-binder interactions [9]. It was observed that electron-rich groups with lone pairs on $\mathrm{O}, \mathrm{N}$, and halogen atoms bind with the $\mathrm{Li}^{+}$cations in $\mathrm{Li}_{2} \mathrm{~S}$ via coordination interactions. The strongest binding moreover was with carbonyl groups $(>\mathrm{C}=\mathrm{O})$ on esters, ketones and amides, where Li-O bonds were observed to be the strongest and most stable interactions. These interactions were primarily due to the hard acid nature of $\mathrm{Li}^{+}$cations, which can bind strongly with hard oxygen donor atoms. Likewise, such interactions were also observed between the $\mathrm{Li}^{+}$cations in LiPSs and the $\mathrm{O}$ in $>\mathrm{C}=\mathrm{O}$ groups. The PAMAM dendrimers used in this study are all rich in carbonyl groups within the dendrimer interior, as well as in the surface groups (G4CMP). In light of this understating, it is concluded that a high density of carbonylcontaining functional groups per dendrimer, along with the three-dimensional, porous architecture of the dendrimers, contributes significantly to the strong binding between the dendrimers and the LiPSs. In contrast, a limited number of such groups in linear polymers result in weaker interactions with the LiPSs. As part of this work, ab-inito simulations are currently underway to calculate the binding energies between a single PAMAM dendrimer and LiPS. It is also anticipated that the interior porosity of the dendrimers physically captures 
the LiPSs in addition to the chemical binding. The pores within the dendrimers are of the order of the dimensions of the polysulfide molecules $(1-2 \mathrm{~nm})[12,13]$.

The SEM images (Figure 3) of the discharged G4CMP electrodes show the presence of large deposits of $\mathrm{Li}_{2} \mathrm{~S}$, confirming the XPS results, and these appear to disappear upon charging, resulting in a morphology much like that of the pristine (new) electrode. Moreover, the pristine electrode shows the highly porous nature, which contributes to its excellent wettability. A large portion of the porosity is retained even after the deposit of discharge products, in contrast to the thick, aggregated deposition of $\mathrm{Li}_{2} \mathrm{~S}$ in the CMC-SBR electrodes (Figure S5c). It should be noted, however, that CMC-SBR may also function well if the carbon host is pretreated to interact well with the binder [22]. Nevertheless, this approach may add to the cost of the final cell.

\subsection{Examination of the poor performance of certain selected dendrimer functional groups as binders}

The poor performance of certain dendrimer functional groups as binders was also investigated and it was concluded that strongly basic $\left(-\mathrm{NH}_{2}\right)$ and acidic $(-\mathrm{COOH})$ groups behave as poor binders due to their undesired interactions with S [15]. To understand the mechanism of the poor binding, an XPS analysis of the pristine electrodes with these binders was conducted (Figure S7). Figure $\mathrm{S} 7 \mathrm{a}$ shows the minor presence of a $\mathrm{S}^{1-}$ species in the $\mathrm{G}_{4} \mathrm{NH}_{2}, \mathrm{G} 4 \mathrm{OH}-\mathrm{NH}_{2}$, and G4SA electrodes - an occurrence not seen in the G4OH, G4CMP, and G4COONa-based electrodes. Toland et al. studied the oxidation of organic compounds with $\mathrm{S}$ in the presence of a base and/or nucleophilic agents [15]. Such interactions usually result in the hydrolysis of the organic compounds to form carboxylates and amides, and the formation of reduced $\mathrm{S}$ species. It is therefore anticipated that the minor quantities of $\mathrm{S}^{1-}$ species observed in the amine $\left(\mathrm{G}_{4} \mathrm{NH}_{2}, \mathrm{G} 4 \mathrm{OH}-\mathrm{NH}_{2}\right)$ and carboxylic acid $(\mathrm{G} 4 \mathrm{SA})$ terminated dendrimer-based electrodes

(Figure S7a) are due to the oxidation of these groups by $\mathrm{S}$, whereby $\mathrm{S}$ was reduced to $\mathrm{S}^{1-}$. The 
oxidized species from the dendrimers could not be discerned due to the large overlap of the relevant peaks with the intact dendrimer peaks in the O1s spectra, suggesting that although these reactions were minor, they do affect the binding properties of the dendrimers with the Sbased electrodes. A similar observation was made with the CMC-SBR binder-based electrodes in Figure S8. Here, the oxidation of the COONa and C-O-H functional groups on the binder with $\mathrm{S}$ would result in the hydrolysis of these groups, thus explaining the poor binding and electrochemical performance of the CMC-SBR-based electrodes. As can be seen from Figure S7b, a $0.5 \mathrm{eV}$ shift towards higher binding energies is observed in the N1s peak of the $\mathrm{G}_{4} \mathrm{NH}_{2}$ dendrimer after binding with the $\mathrm{C} / \mathrm{S} / \mathrm{MWCNT}$ composites, whereas the G4SA and $\mathrm{G} 4 \mathrm{OH}-\mathrm{NH}_{2}$-based electrodes show shifts (about $1 \mathrm{eV}$ ) similar to those observed in the G4OH, G4CMP, and G4COONa electrodes. The C1s spectra (Figure S7c) show the presence of dendrimers in the electrodes and similar relative differences in peak intensities of the C-N peaks for all of the $\mathrm{G} 4 \mathrm{NH}_{2}, \mathrm{G} 4 \mathrm{SA}$, and $\mathrm{G} 4 \mathrm{OH}-\mathrm{NH}_{2}$ dendrimers after binding with the C/S/MWCNT composites due to the low dendrimer concentration, as was observed for the G4OH, G4CMP and G4COONa electrodes. The O1s spectra (Figure S7d) are also similar to that of the G4OH, G4CMP and G4COONa electrodes.

\section{Conclusion}

In conclusion, new binder architecture is proposed for high S-loading cathodes in Li-S batteries based on hyperbranched macromolecules, with PAMAM dendrimers utilized as model systems. Without involving complex synthesis/modification steps for the preparation of the cathode carbon host material, a superior performance of high areal capacity S cathodes was demonstrated using dendrimer-based binders. Moreover, the dendrimers are readily soluble in water, thus eliminating the need to use costly, toxic and high boiling point solvents for the slurry preparation. Utilizing the high degree of surface functionalities, interior porosities, and polarity of the PAMAM dendrimers, high S-loading cathodes $\left(>4 \mathrm{mg} \mathrm{cm}^{-2}\right)$ 
were obtained with high S content (> $68 \mathrm{wt} \%$ ), excellent rate capability and stable cyclability. The cell with the G4CMP binder achieved a high S-loading of $4.38 \mathrm{mg} \mathrm{cm}^{-2}$, a high areal capacity of $4.32 \mathrm{mAh} \mathrm{cm}^{-2}$, and a high specific capacity of $1045 \mathrm{mAh} \mathrm{g}^{-1}$ at a C/20 discharge rate, with a capacity retention of $\sim 640 \mathrm{mAh} \mathrm{g}^{-1}$ after 100 cycles ( $98 \%$ of the original capacity) at a $\mathrm{C} / 5$ discharge rate. The superior and stable electrochemical performance of the dendrimer-based binders for high S loadings, in contrast with linear water-soluble CMC-SBR binders, is attributed to better interfacial interactions between the high density of surface functional groups of the dendrimers and the $\mathrm{C} / \mathrm{S} / \mathrm{MWCNT}$ composite materials, as well as better electrolyte wetting due to the dendrimer spherical molecular, porous architectures. Furthermore, the dendrimer-based binders also physically and chemically trapped the polar LiPSs, thus enhancing the cell cycling stability. It was concluded that acidic $(\mathrm{COOH})$ and basic $\left(\mathrm{NH}_{2}\right)$ functional groups serve as poor binders for $\mathrm{S}$ cathodes due to their detrimental oxidation by $\mathrm{S}$. This new binder approach presented here offers a facile method of fabricating high-areal-capacity S cathodes, as well as introduces novel binder architecture with CNDPs, potentially applicable to electrochemical systems beyond Li-S batteries. Future research will focus on designing commercially viable (easily synthesized, lower cost) hyperbranched macromolecular-based binder systems for use in a wider range of energy storage systems.

\section{Acknowledgements}

This work was supported by the Assistant Secretary for Energy Efficiency and Renewable Energy, Office of Vehicle Technologies of DOE under Contract No. DEAC02-5CH11231 for PNNL and under the DEAC02-98CH10886 Battery Materials Research (BMR) program (for D.L. and J.X.), and the U.S. Department of Energy (DOE) Laboratory Directed Research and Development funding at Pacific Northwest National Laboratory (PNNL). A portion of the research was performed using Environmental Molecular Sciences Laboratory (EMSL), a national scientific user facility sponsored by the DOE Office of Biological and Environmental Research and located at PNNL. PNNL is operated for the DOE by Battelle. P.B. is grateful for support from a Linus Pauling Distinguished Postdoctoral Fellowship at PNNL. P.B. and M.I.N. contributed equally to this work. 


\section{Appendix: Supplementary material}

Figure S1. TGA analysis of the C/S/MWCNT composite and the different dendrimers and CMC-SBR-based electrodes. Figure S2. High-resolution (a) S2p, (b) N1s, (c) C1s, and (d) O1s XPS spectra of G4COONa dendrimer-based electrodes. Figure S3. ATR-FTIR spectra of dendrimer-based cathodes. Table S1. ATR-FTIR peaks of the G4OH, G4CMP and G4COONa dendrimers Figure S4. Electrochemical cycling and capacity-voltage profiles of the G4COONa dendrimer binder-based Li-S cells. Figure S5. (a) Electrochemical performance of the CMC-SBR-based cell, (b) cycling stability comparison of CMC-SBRbased cells with dendrimer-based cells, and (c) SEM image of the CMC-SBR-based cathode after 50 cycles. Scale bar: $10 \mu \mathrm{m}$ Figure S6. Rate performance of the G4CMP binder-based Li-S cell. Figure S7. High-resolution (a) S2p, (b) N1s, (c) C1s, and (d) O1s XPS spectra of the poor binding dendrimer-based pristine electrodes. Figure S8. High-resolution (a) S2p, (b) C1s, and (c) O1s XPS spectra of the CMC-SBR binder-based pristine electrodes.

\section{References}

[1] a) S. S. Zhang, J. A. Read, J. Power Sources 200 (2012) 77-82; b) R. Chen, T. Zhao, F. Wu, Chem. Commun. 51 (2015) 18-33; c) A. Manthiram, Y. Fu, S. H. Chung, C. Zu, Y. S. Su, Chem. Rev. 114 (2014) 11751-11787; d) A. Manthiram, S. H. Chung, C. Zu, Adv. Mater. 27 (2015) 1980-2006; e) R. Demir-Cakan, M. Morcrette, Gangulibabu, A. Guéguen, R.

Dedryvère, J.-M. Tarascon, Energy Environ. Sci. 6 (2013) 176-182; f) D. Bresser, S. Passerini, B. Scrosati, Chem. Commun. 49 (2013) 10545-10562.

[2] P. G. Bruce, S. A. Freunberger, L. J. Hardwick, J. M. Tarascon, Nat. Mater. 11 (2012) $19-29$.

[3] X. Ji, L. F. Nazar, J. Mater. Chem. 20 (2010) 9821-9826.

[4] J. Sun, Y. Huang, W. Wang, Z. Yu, A. Wang, K. Yuan, Electrochim. Acta 53 (2008) 7084-7088. 
S. S. Zhang, J. Electrochem. Soc. 159 (2012) A920-A923.

[6] Y. Huang, J. Sun, W. Wang, Y. Wang, Z. Yu, H. Zhang, A. Wang, K. Yuan, J. Electrochem. Soc. 155 (2008) A764-A767.

[7] J. Pan, G. Xu, B. Ding, J. Han, H. Dou, X. Zhang, RSC Adv. 5 (2015) 13709-13714.

[8] Y. Jung, S. Kim, Electrochem. Commun. 9 (2007) 249-254.

[9] Z. W. Seh, Q. Zhang, W. Li, G. Zheng, H. Yao, Y. Cui, Chem. Sci. 4 (2013) 36733766.

[10] a) P. Bhattacharya, N. K. Geitner, S. Sarupria, P. C. Ke, Phys. Chem. Chem. Phys. 15 (2013) 4477-4490; b) D. A. Tomalia, H. Baker, J. Dewald, M. Hall, G. Kallos, S. Martin, J. Roeck, J. Ryder, P. Smith, Polym. J. 17 (1985) 117-132.

[11] a) J. Song, T. Xu, M. L. Gordin, P. Zhu, D. Lv, Y.-B. Jiang, Y. Chen, Y. Duan, D. Wang, Adv. Funct. Mater. 24 (2014) 1243-1250; b) J. Song, M. L. Gordin, T. Xu, S. Chen, Z. Yu, H. Sohn, J. Lu, Y. Ren, Y. Duan, D.Wang, Angew. Chem. Int. Ed. 54 (2015) 4325-4329. doi:10.1002/anie.201411109

[12] P. K. Maiti, T. Çağın, S.-T. Lin,W. A. Goddard, Macromolecules 38 (2005) 979-991.

[13] a) M. Vijayakumar, N. Govind, E. Walter, S. D. Burton, A. Shukla, A. Devaraj, J. Xiao, J. Liu, C. Wang, A. Karim, S. Thevuthasan, Phys. Chem. Chem. Phys. 16 (2014) 10923-10932; b) O. Knop, R. J. Boyd, S. C. Choi, J. Am. Chem. Soc. 110 (1988) 7299-7301; c) A. I. Boldyrev, J. Simons, J. Chem. Phys. 99 (1993) 8793-8804.

[14] a) J. P. Boudou, M. Chehimi, E. Broniek, T. Siemieniewska, J. Bimer, Carbon 41 (2003) 1999-2007; b) Y. Y. Li, S. D. Bae, A. Sakoda, M. Suzuki, Carbon 39 (2001) 91-100.

[15] W. G. Toland, D. L. Hagmann, J. B. Wilkes, F. J. Brutschy, J. Am. Chem. Soc. 80 (1958) 5423-5427.

[16] Y.-S. Su, A. Manthiram, Nat. Commun. 3 (2012) 1166-1-6.

[17] X. Liang, C. Hart, Q. Pang, A. Garsuch, T. Weiss, L. F. Nazar, Nat. Commun. 6 (2015), 5682-1-8. 
[18] N. Azimi, Z. Xue, I. Bloom, M. L. Gordin, D. Wang, T. Daniel, C. Takoudis, Z. Zhang, ACS Appl. Mater. Interfaces 7 (2015) 9169-9177.

[19] A. S. J. P. Contour, M. Froment, M. Garreau, J. Thevenin, D. Warin. J. Microsc. Spectrosc. Electron. 4 (1979) 483-491.

[20] a) X. Ji, K. T. Lee, L. F. Nazar, Nat. Mater. 8 (2009) 500-506; b) H. Wang, Y. Yang, Y. Liang, J. T. Robinson, Y. Li, A. Jackson, Y. Cui, H. Dai, Nano Lett. 11 (2011) 2644-2647; c) S.-H. Chung, A. Manthiram, Adv. Mater. 26 (2014) 7352-7357; c) K. Park, J. H. Cho, J.-H. Jang, B.-C. Yu, A. T. De La Hoz, K. M. Miller, C. J. Ellison, J. B. Goodenough, Energy Environ. Sci. 8 (2015) 2389-2395.

[21] Z. W. Seh, H. Wang, P.-C. Hsu, Q. Zhang, W. Li, G. Zheng, H. Yao, Y. Cui, Energy Environ. Sci. 7 (2014) 672-676.

[22] D. Lv, J. Zheng, Q. Li, X. Xie, S. Ferrara, Z. Nie, L. B. Mehdi, N. D. Browning, J.-G. Zhang, G. L. Graff, J. Liu, J. Xiao, Adv. Energy Mater., DOI: 10.1002/aenm.201402290. 


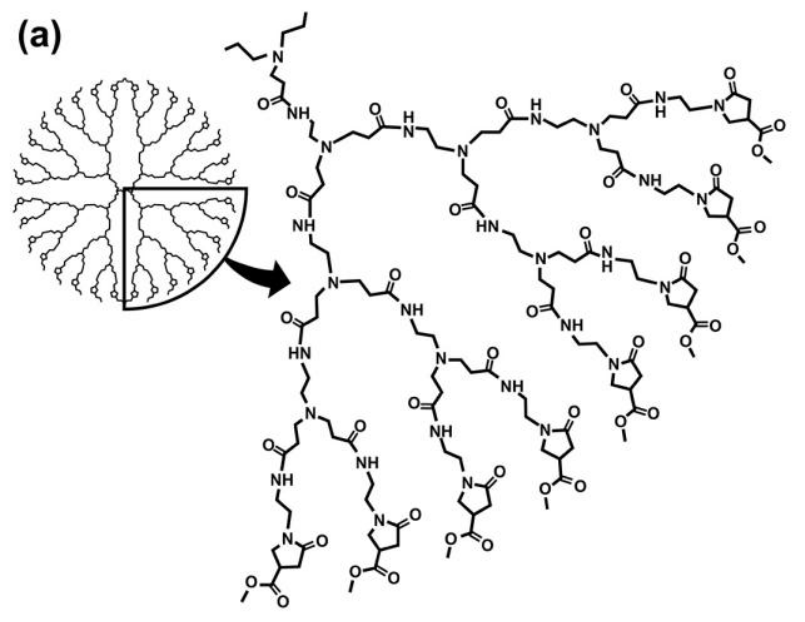

(c)

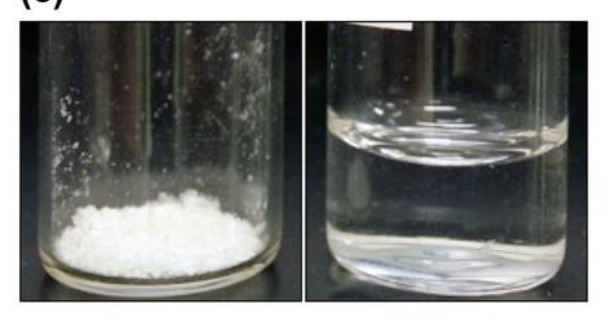

(b)

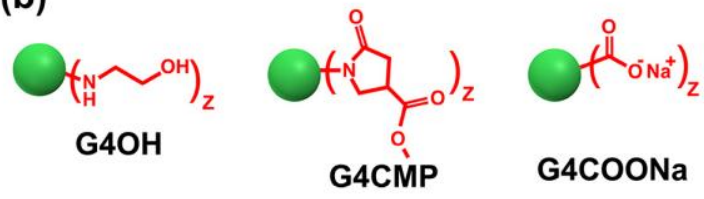

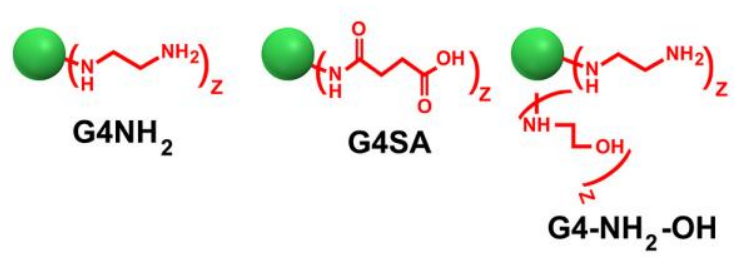

(d)

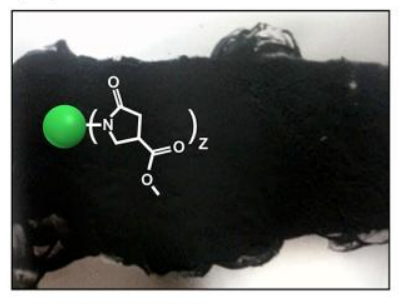

(e)

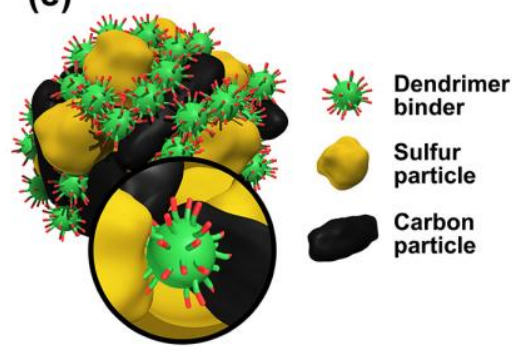

Scheme 1. (a) Schematic of a generation 3 PAMAM 4-carbomethoxy pyrrolidone dendrimer (G3CMP) and a zoomed-in image of its branch, (b) matrix of surface groups analyzed (c) image showing dry G4CMP dendrimer and the dendrimer dissolved forming an aqueous solution, (d) image of electrode coated with a slurry having the G4CMP binder, and (e) proposed cartoon of dendrimer-C/S/MWCNT interactions. 


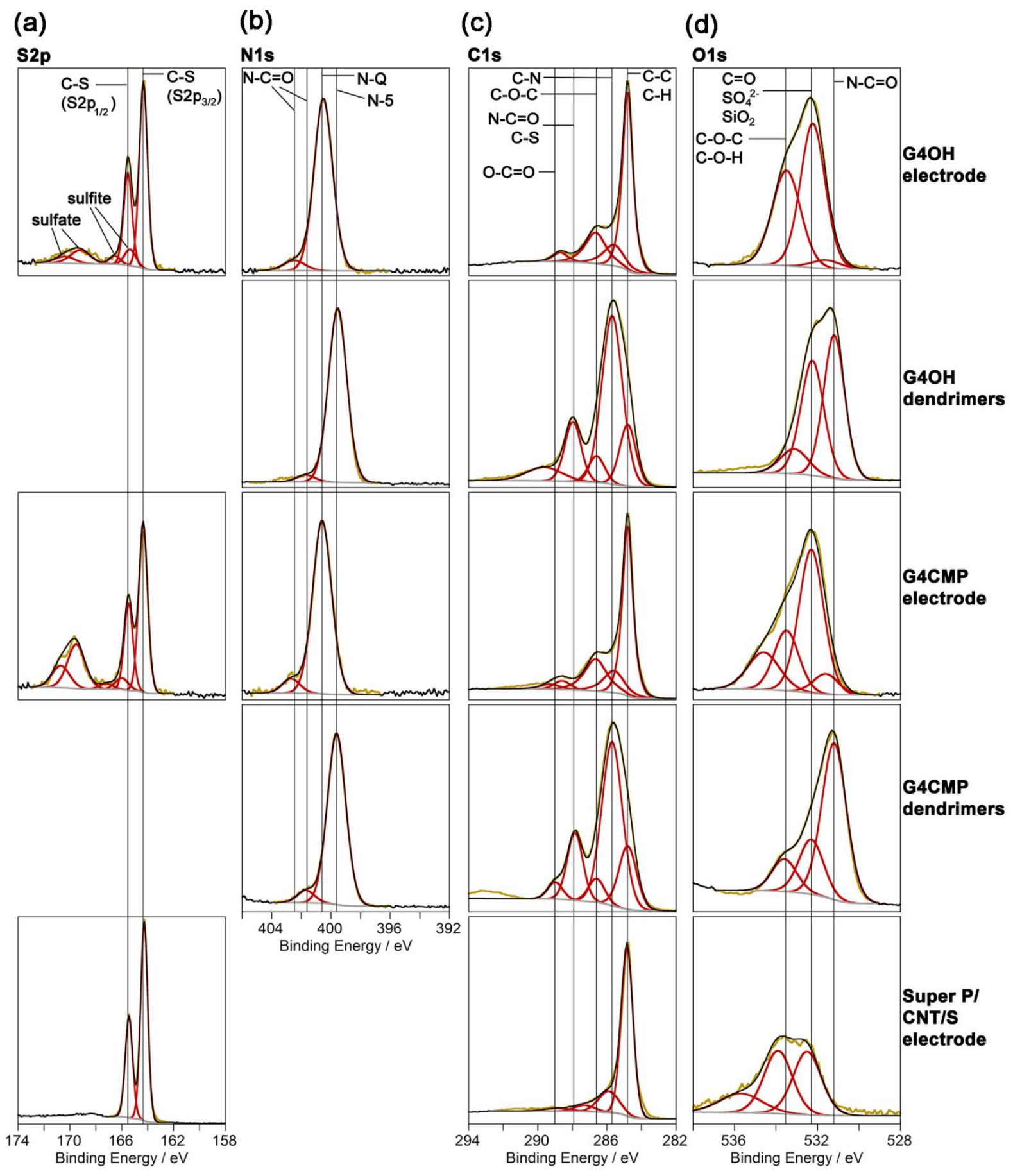

Figure 1. High-resolution (a) S2p, (b) N1s, (c) C1s, and (d) O1s XPS spectra of dendrimerbased electrodes. 
(a)

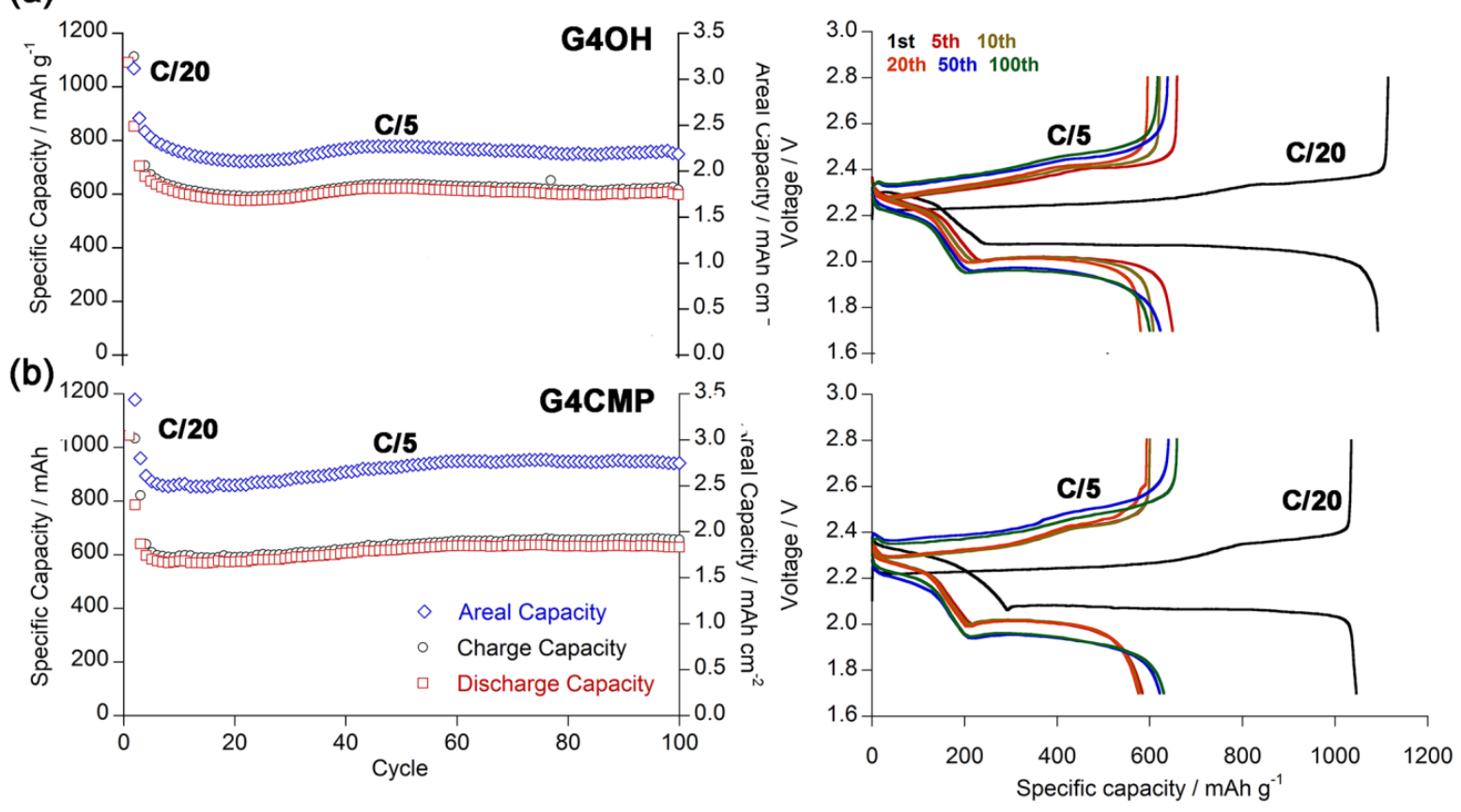

Figure 2. Electrochemical cycling and capacity-voltage profiles of (a) G4OH and (b) G4CMP dendrimer binder-based Li-S cells.
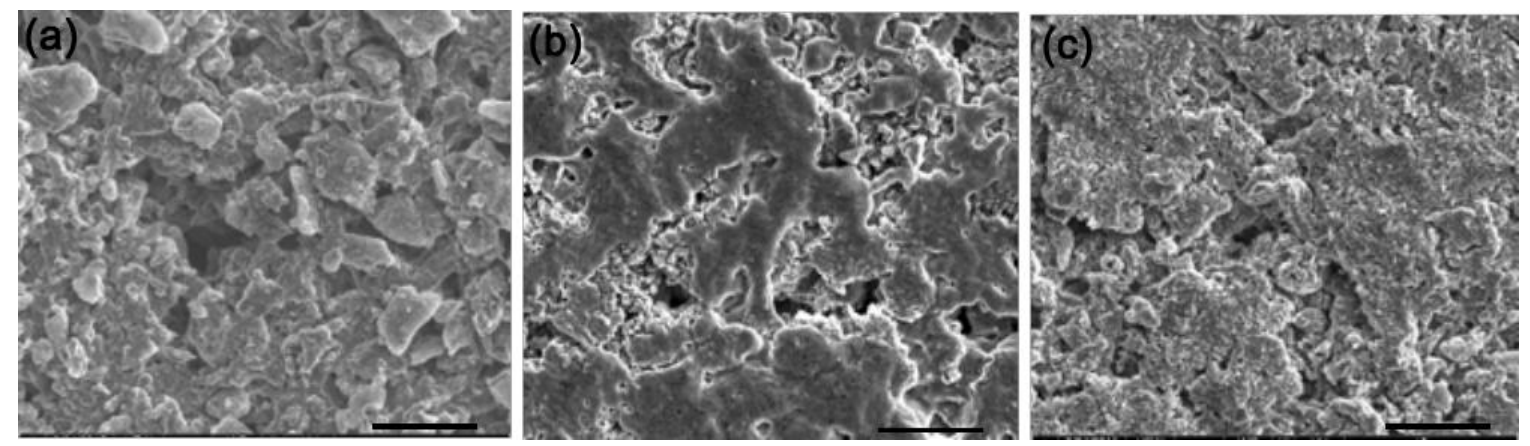

Figure 3. SEM images of the cathodes with the G4CMP binders: (a) pristine, (b) discharged state after 50 cycles, and (c) charged state after 50 cycles. Scale bars: $10 \mu \mathrm{m}$ 
(a)

\section{S2p}
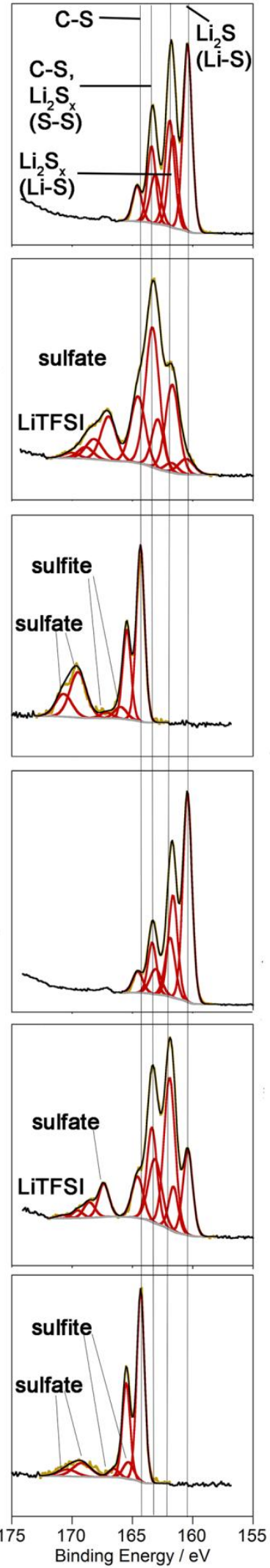

(b)

$01 \mathrm{~s}$
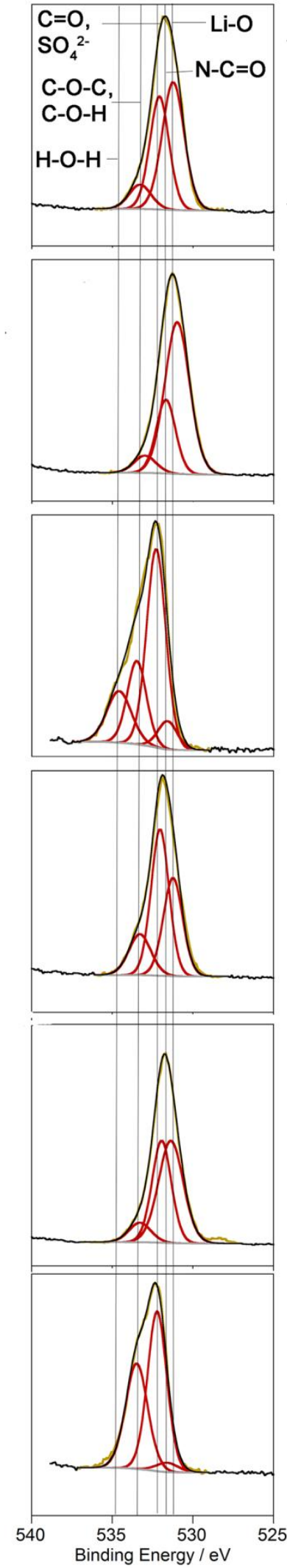

(c)

L1s

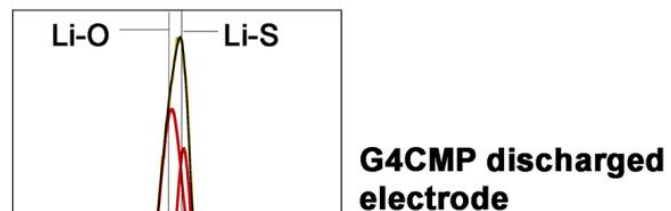

electrode

G4CMP charged electrode

G4CMP pristine electrode

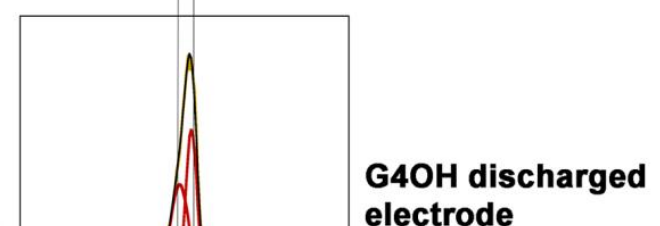

electrode

G4OH charged electrode

G4OH pristine electrode

Figure 4. High-resolution (a) S2p, (b) O1s, and (c) L1s XPS spectra of G4OH and G4CMP dendrimer-based cycled electrodes. 


\section{Graphical Abstract}

The critical nanoscale design parameters of dendrimers are exploited as functional watersoluble binders for high sulfur loading lithium-sulfur batteries. The high functional group density, high curvature and porosity, polarity, and ample nitrogen and oxygen functional groups in the dendrimers enabled strong dendrimer interactions with the carbon-sulfur composites, and superior cyclability compared to linear water-soluble binders such as CMCSBR.

Keyword. PAMAM dendrimers, lithium-sulfur batteries, binders, energy storage, high sulfur loading

P. Bhattacharya*, M. I. Nandasiri, D. Lv, A. M. Schwarz, J. T. Darsell, W. A. Henderson, D. A. Tomalia, J. Liu, J.-G. Zhang, J. Xiao*

\section{Polyamidoamine Dendrimer-Based Binders for High-Loading Lithium-Sulfur Battery} Cathodes

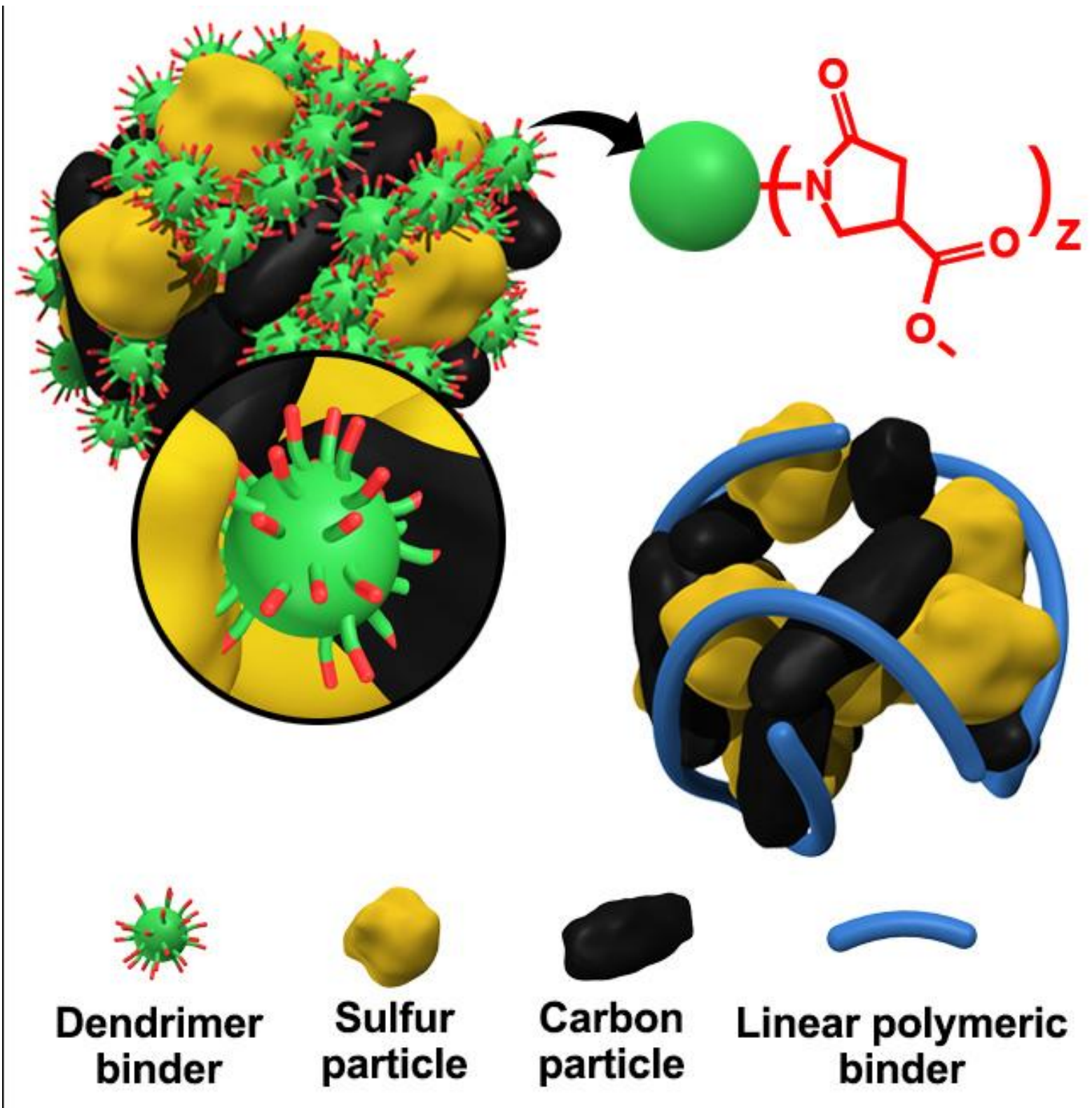

